\title{
Caracterización de aguas subterRáneas en el municipio BUCHIVACOA (VENEZUELA) CON FINES DE TRATAMIENTO
}

\author{
Characterization of underground WATER For FUtURE tREATMENT \\ PURPOSES IN BUCHIVACOA MUNICIPALITY (VENEZUELA)
}

Noel Acacio Chirino*
Jonnattan Cancino Camperos
Manuel Molina Céspedes

Recibido: 19 de marzo de 2018

Aceptado: 18 de mayo de 2018

\section{Resumen}

Se realizó una caracterización fisicoquímica y microbiológica para clasificar las aguas subterráneas de tres zonas del municipio Buchivacoa con el fin de proponer un esquema de tratamiento. Se realizaron muestreos por bombeo en 32 pozos y análisis de laboratorio para determinar las características fisicoquímicas y microbiológicas del agua, que se compararon con las normas vigentes para agua potable. Los análisis indican que algunos pozos tienen contenidos de dureza, hierro y manganeso que están sobre el tope permitido por las normas venezolanas. Igualmente, el estudio determinó que el agua de los pozos es salobre. Los resultados para coliformes, Escherichia coli, Salmonella y esporas de bacterias formadoras de viscosidad fueron negativos. Las aguas se pueden clasificar en los subtipos 1B y 1C. El esquema de tratamiento sugerido lo conforman procesos de filtración, ablandamiento, aireación, ósmosis inversa y cloración.

Palabras clave: agua, caracterización, pozos, procesos, tratamiento.

\section{Abstract}

A physicochemical and microbiological characterization was carried out to classify groundwater in three areas of Buchivacoa municipality in order to propose a treatment scheme. Sampling was done by pumping in 32 wells and laboratory analysis to determine the physicochemical and

\footnotetext{
* Ingeniero químico, magíster Scientiarum en Gerencia de Calidad y Productividad, magíster en Análisis de Procesos de la Industria Química, especialista en Ingeniería de Procesos. Investigador PEll categoría B, profesor asistente del Departamento de Química, Área de Tecnología, Universidad Nacional Experimental Francisco de Miranda, Santa Ana de Coro, estado Falcón, Venezuela. ORCID: https://orcid.org/0000-0002-0795-7628. noelacacio@gmail.com

** Ingeniero químico, magíster en Ingeniería de Procesos, especialista en Ingeniería de Procesos. Investigador PEll categoría A-2, profesor agregado del Departamento de Química, Área de Tecnología, Universidad Nacional Experimental Francisco de Miranda, Santa Ana de Coro, estado Falcón, Venezuela. ORCID: https://orcid.org/00000003-1565-0826. jonnattancancino@gmail.com

*** Licenciado en Ciencias Ambientales, especialista en Calidad Ambiental. Investigador PEll categoría A-2, asistente de investigación del Centro de Investigaciones en Ciencias Básicas, Universidad Nacional Experimental Francisco de Miranda, Santa Ana de Coro, estado Falcón, Venezuela. ORCID: https://orcid.org/0000-0003-44942350. manuelmolina230@ hotmail.com
} 
microbiological characteristics of the water, which were compared with the current regulations for drinking water. The analyzes indicate that some wells have hardness, iron and manganese contents that are above the maximum permitted by Venezuelan standards. Likewise, the study determined that the water in the wells is brackish. The results for coliforms, Escherichia coli, Salmonella and spores of viscosity-forming bacteria were negative. Waters can be classified in sub types $1 \mathrm{~B}$ and $1 \mathrm{C}$. The suggested treatment scheme is made up of filtration, softening, aeration, reverse osmosis and chlorination processes.

Keywords: water, characterization, wells, processes, treatment.

\section{INTRODUCCIÓN}

Las comunidades del municipio Buchivacoa (estado Falcón, Venezuela) cuentan con una serie de pozos de agua subterráneas que son las fuentes de suministro de agua de los habitantes. El agua es extraída y almacenada, pero no es utilizada para el consumo humano, sino para el suministro de agua de los animales y, por medio de sistemas de riego, para los sembradíos de los conuqueros. Los pozos no se encuentran conectados a un sistema de distribución de agua potable. La distribución de agua potable en el municipio se realiza principalmente por cisternas, lo que genera un gasto económico a la alcaldía.

Los habitantes de Buchivacoa se ven afectados directamente por el uso de cisterna, pues para hacer llegar el líquido a los hogares, necesitan "tanques de almacenamiento con la capacidad suficiente para cubrir el consumo por lo menos cinco días que es la frecuencia con que el camión puede abastecer las casas" (J. Benítez, entrevista personal, enero 20 de 2013). Cabe destacar que estas aguas no tienen ningún tipo de tratamiento, ni se cuenta con los análisis de laboratorio correspondientes.

La selección de las tecnologías para el establecimiento del sistema de potabilización se basa específicamente en los beneficios que proporcionan diversos factores como, por ejemplo, costo de la tecnología, accesibilidad, eficiencia, facilidad de operación y factibilidad (Reyes, 2016)

Al respecto del tratamiento del agua, el Centro Panamericano de Ingeniería Sanitaria y Ciencias del Ambiente (2004) establece que:

Los objetivos del tratamiento para mejorar la calidad del agua de abastecimiento son de tipo: a) higiénico: remover bacterias y elementos venenosos o nocivos, así como resolver la mineralización excesiva y las concentraciones elevadas de compuestos orgánicos, protozoarios y otros microorganismos, b) estético: corregir el color, la turbidez, el olor y el sabor, c) económico: reducir la corrosividad, la dureza, el color, la turbidez; reducir las concentraciones de hierro y manganeso, resolver problemas de olor y sabor, etcétera. (p. 416)

La utilización de las técnicas de desalinización de aguas subterráneas en zonas costeras se ha incrementado en los últimos años, con el fin de mitigar la falta de recursos hídricos en zonas proclives a la escasez o de pocas precipitaciones, lo que le otorga un valor agregado a la proposición de esquemas de potabilización para el aprovechamiento de fuentes hídricas en esas localidades que durante décadas han sufrido problemas relacionados con el acceso al agua potable. Esto le confiere un valor agregado a esta línea de investigación, la cual ha sido escasamente abordada, sobre todo en localidades tropicales y con características similares a las presentadas en el presente estudio.

Como respuesta al cambio climático, en América Latina se ha promovido la asistencia técnica y el financiamiento de sistemas de manejo de fuentes de aguas subterráneas para así garantizar las actividades de agricultura y ganadería. En este contexto y con la finalidad de generar instrumentos 
técnicos que fortalezcan las actividades, se publicó el Manual de Aguas Subterráneas, en el que se "describen aspectos fundamentales de la ciencia hidrogeológica y de su aplicación práctica en la producción agropecuaria del Uruguay"(Collazo y Montaño, 2012, p. 9-10). Este manual responde a la fuerte demanda de obras de captación de agua subterránea y a la necesidad de producir materiales técnicos sobre los recursos hídricos subterráneos, que son recursos estratégicos para el desarrollo socioeconómico de los países. Profundizar en su conocimiento es indispensable para alcanzar una gestión sostenible.

Un proyecto de investigación realizado en el estado de Falcón, Evaluación de la Posible Intrusión Marina y Salinización de Pozos Costeros en Áreas Piloto al Norte de Tocópero y Puerto Cumarebo, Estado Falcón, establece que la dinámica de las aguas subterráneas es de difícil comprensión, y que se requiere para ello una importante cantidad de datos, ya que ni el agua ni la estructura del subsuelo se ven directamente. En el subsuelo de las regiones costeras existe una interfase o cuña salina:

[...] que está delimitada por la región del subsuelo donde coinciden el agua dulce, procedente de la recarga continental, y el agua salada, también subterránea, que se infiltra a través del suelo marino. En la naturaleza se establece un equilibrio entre el agua dulce y el agua salada; cuando este equilibrio se rompe el agua salada invade el acuífero elevando el nivel de sales del agua dulce utilizable. (Universidad Simón Bolívar, 2006, p. 1)

Durante el desarrollo del proyecto se recolectaron muestras de agua de los pozos y manantiales en estudio para los análisis en los laboratorios y determinar parámetros de calidad del agua.

Se obtuvieron datos importantes de parámetros como $\mathrm{pH}$, salinidad, cloruros, conductividad, turbidez, color, metales mayoritarios, que permiten comparar el comportamiento de esas fuentes de aguas subterráneas de la zona costera central con los pozos del municipio Buchivacoa, zona costera occidental del estado Falcón. La información obtenida en este proyecto permitió realizar campañas de concienciación de los pobladores y agricultores usuarios de los recursos hídricos subterráneos.

Considerando la importancia de las aguas subterráneas en el suministro de agua para diferentes usos, surge la necesidad identificar los tratamientos para el aprovechamiento de las fuentes de aguas subterráneas por parte de las comunidades directamente beneficiadas.

Se realizó la caracterización fisicoquímica y microbiológica de las fuentes de aguas de las comunidades objeto a estudio, para: a) determinar los tipos de tratamientos adecuados a este tipo de aguas; b) clasificar las aguas de cada pozo de acuerdo al Decreto 883, Normas para la Clasificación y Control de Cuerpos de Aguas y Vertidos o Efluentes Líquidos, y c) identificar las posibles propuestas que conforman el esquema para el aprovechamiento de las fuentes de aguas subterráneas.

Esta investigación comprende la caracterización fisicoquímica y microbiológica de los 32 pozos que están a resguardo de la comunidad del municipio Buchivacoa mediante: a) medición de parámetros en campo, b) análisis de laboratorio y c) georeferenciaron de los pozos de la localidad en tres grandes zonas de acuerdo a la cercanía de los mismos: zona Capatárida, zona Zazárida y zona Borojó y Seque. Los análisis de los resultados surgen de la comparación de los mismos con las normas venezolanas vigentes para agua potable y de investigaciones similares que permitieron la clasificación y soportaron la propuesta del esquema de tratamiento.

\section{Metodología}

El muestreo y análisis de los pozos estudiados se realizó durante los meses marzo y junio y contempló la realización de inventarios de los pozos de agua subterránea ubicados en el municipio Buchivacoa, con el fin de recaudar datos de cada uno de los pozos que se encuentran en el municipio. 
La información referente a cada pozo fue georeferenciada con GPS (Garmin-ETREX 20) y luego con el sistema de coordenadas UTM (proyección transversal universal de Mercartor) con el fin de actualizar la información acerca de los pozos y ordenar los datos para futuras investigaciones.

Dado que la problemática presentada en el municipio Buchivacoa es de abastecimiento y acceso a agua potable, los análisis se realizaron con base en las normas nacionales, como lo establecido por la Gaceta Oficial de la República de Venezuela n. 36395 de 1998, Normas Sanitarias de Calidad del Agua Potable, en la que se establece los criterios de análisis, métodos de muestreo de aguas subterráneas y parámetros necesarios. Igualmente, se realizaron estudios fisicoquímicos que permitieron clasificar las aguas y ayudaron a plantear alternativas para la potabilización (véase tablas 1, 2 y 3 ).

Tabla 1. Parámetros medidos en campo

\begin{tabular}{ll}
\hline \multicolumn{1}{c}{ Parámetro } & \multicolumn{1}{c}{ Equipo empleado } \\
\hline Conductividad & Conductímetro Sartorius modelo PT-20/C \\
Temperatura & Conductímetro Sartorius modelo PT-20/C \\
Salinidad & Conductímetro Sartorius modelo PT-20/C \\
$\mathrm{pH}$ & $\mathrm{pH}$ metro. PCE Instruments. PCE-PH22 \\
Sólidos disueltos totales & Conductímetro Sartorius modelo PT-20/C \\
Oxígeno disuelto & Medidor de oxígeno disuelto Trans Instruments HD3030 \\
\hline
\end{tabular}

Tabla 2. Parámetros fisicoquímicos

\begin{tabular}{|c|c|c|}
\hline Parámetros & Método analítico & Norma \\
\hline Alcalinidad & Volumétrico & Standard methods 10112 \\
\hline Conductividad & Conductimétrico & Standard methods 02041 \\
\hline $\mathrm{Ph}$ & Electrométrico & Standard methods 10301 \\
\hline Sólidos totales disueltos & Potenciométrico & Standard methods 10471 \\
\hline Salinidad & Potenciométrico & Standard methods 03210 \\
\hline Oxígeno disuelto & Potenciométrico & Standard methods 11203 \\
\hline Acidez & Volumétrico & Covenin 2187-84 \\
\hline Temperatura & Potenciométrico & Standard methods 10203 \\
\hline Sólidos totales suspendidos & Gravimétrico & Covenin $2341-86$ \\
\hline Dureza total & Volumétrico & Standard methods 10603 \\
\hline Dureza cálcica & Volumétrico & Standard methods 21109 \\
\hline Dureza magnésica & Volumétrico & Standard methods 12101 \\
\hline Nitrógeno total & Kjeldhal & Standard methods 17302 \\
\hline Fosforo & Espectrofotométrico & Covenin 3051-93 \\
\hline Sulfatos & Espectrofotométrico & Standard methods 16302 \\
\hline Cloruros & Volumétrico & Standard methods 17204 \\
\hline Turbidez & Nefelométrico & Covenin 2186-84 \\
\hline Potasio & Espectrofotométrico & Standard methods 19001 \\
\hline Sodio & Espectrofotométrico & Standard methods 11003 \\
\hline Hierro & Espectrofotométrico & Covenin $2120-84$ \\
\hline Níquel & Espectrofotométrico & Covenin $2124-84$ \\
\hline Manganeso & Espectrofotométrico & Standard methods 21103 \\
\hline Cobre & Espectrofotométrico & Standard methods 29006 \\
\hline Zinc & Espectrofotométrico & Standard methods 30004 \\
\hline
\end{tabular}


Tabla 3. Parámetros microbiológicos

\begin{tabular}{lll}
\hline \multicolumn{1}{c}{ Parámetros } & \multicolumn{1}{c}{ Método analítico } & \multicolumn{1}{c}{ Norma } \\
\hline Coliformes totales, (NMP/100mL) & $\begin{array}{l}\text { Técnica de diluciones en tubo múltiple y } \\
\text { siembra en placa } \\
\text { Técnica de diluciones en tubo múltiple y y }\end{array}$ & Covenin 1104-1996 \\
Escherichia coli, (NMP/mL) & $\begin{array}{l}\text { Siembra en placa } \\
\text { Incubación en medios líquidos }\end{array}$ & Covenin 1291-88 \\
$\begin{array}{l}\text { Salmonella en } 25 \mathrm{~mL} \\
\begin{array}{l}\text { Esporas de bacterias formadoras de } \\
\text { viscosidad, }(\mathrm{esp} / \mathrm{mL})\end{array}\end{array}$ & Incubación en placa & Covenin 2499-88 \\
\hline
\end{tabular}

Todos los parámetros se realizaron por triplicado y posteriormente se les aplicó el análisis estadístico (media, desviación estándar y coeficiente de variación).

\section{Resultados}

Con la delimitación del municipio en tres grandes zonas de estudio y una vez obtenidas las coordenadas de cada pozo, se procesaron los datos en el sistema de información geográfica QGIS (versión 2.12.1), con la finalidad de tener un uso sistematizado de la información y su actualización como base de datos para los organismos del Estado que manejan información respecto a la calidad ambiental y condiciones de la zona estudiada.

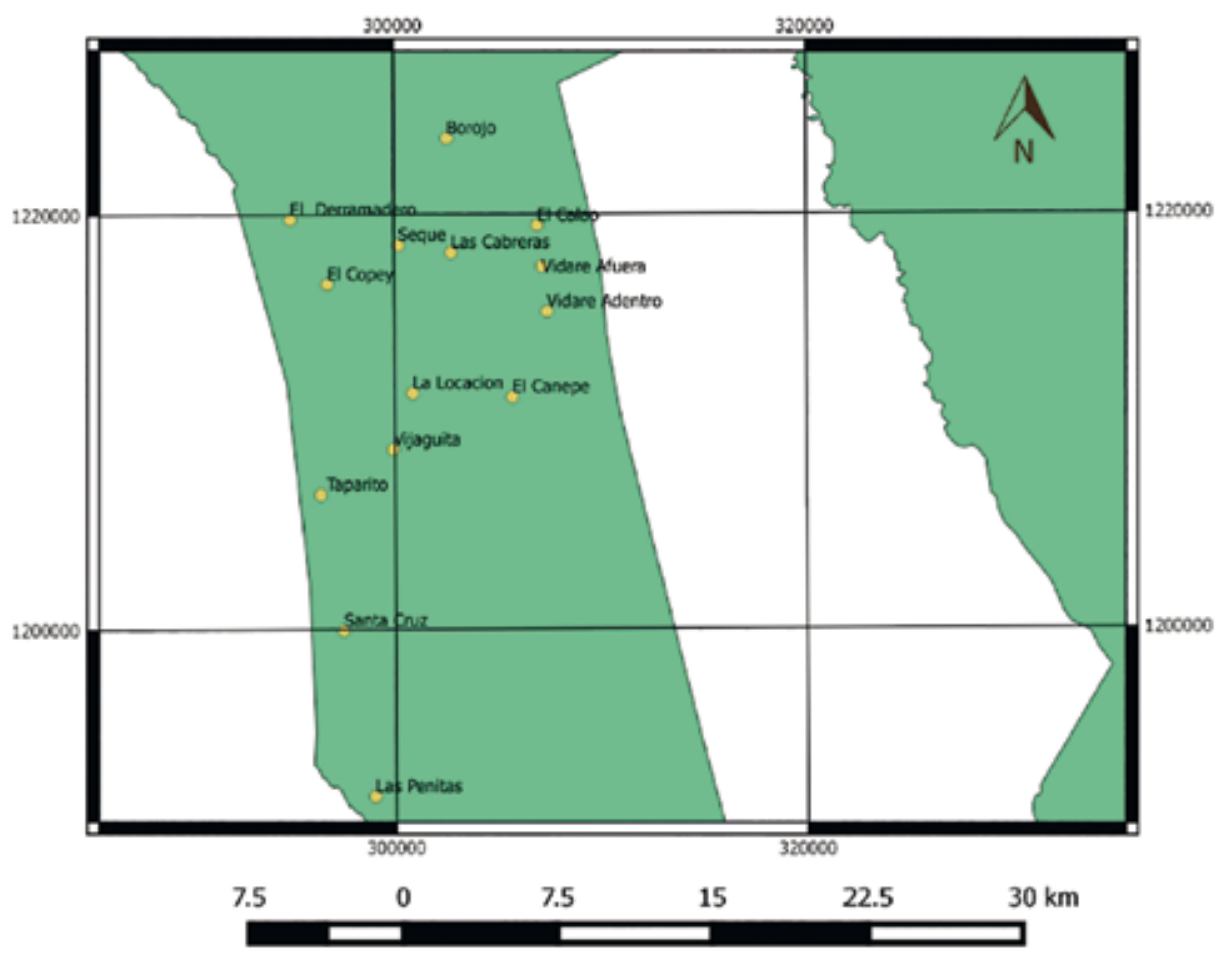

Figura 1. Ubicación de los pozos zona Borojó y Seque.

Fuente: elaborado con datos tomados del SIG QGIS V2.12.1. 


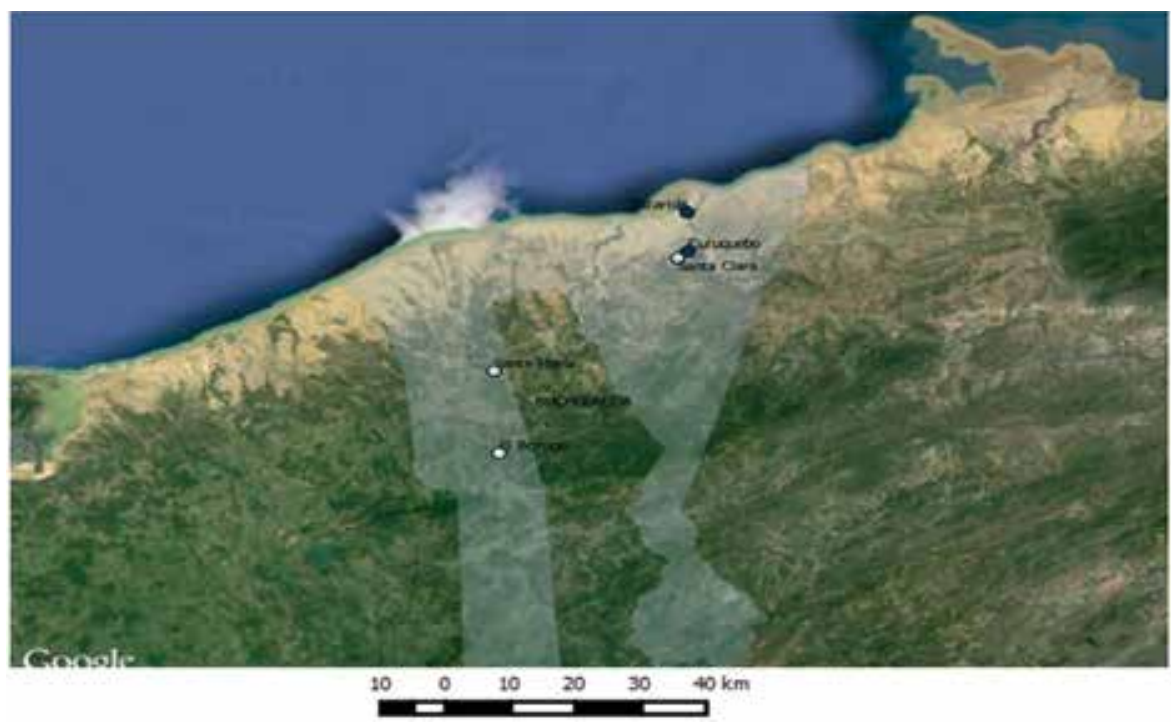

Figura 2. Ubicación de los pozos zona Zazárida.

Fuente: elaborado con datos tomados del SIG QGIS V2.12.1.

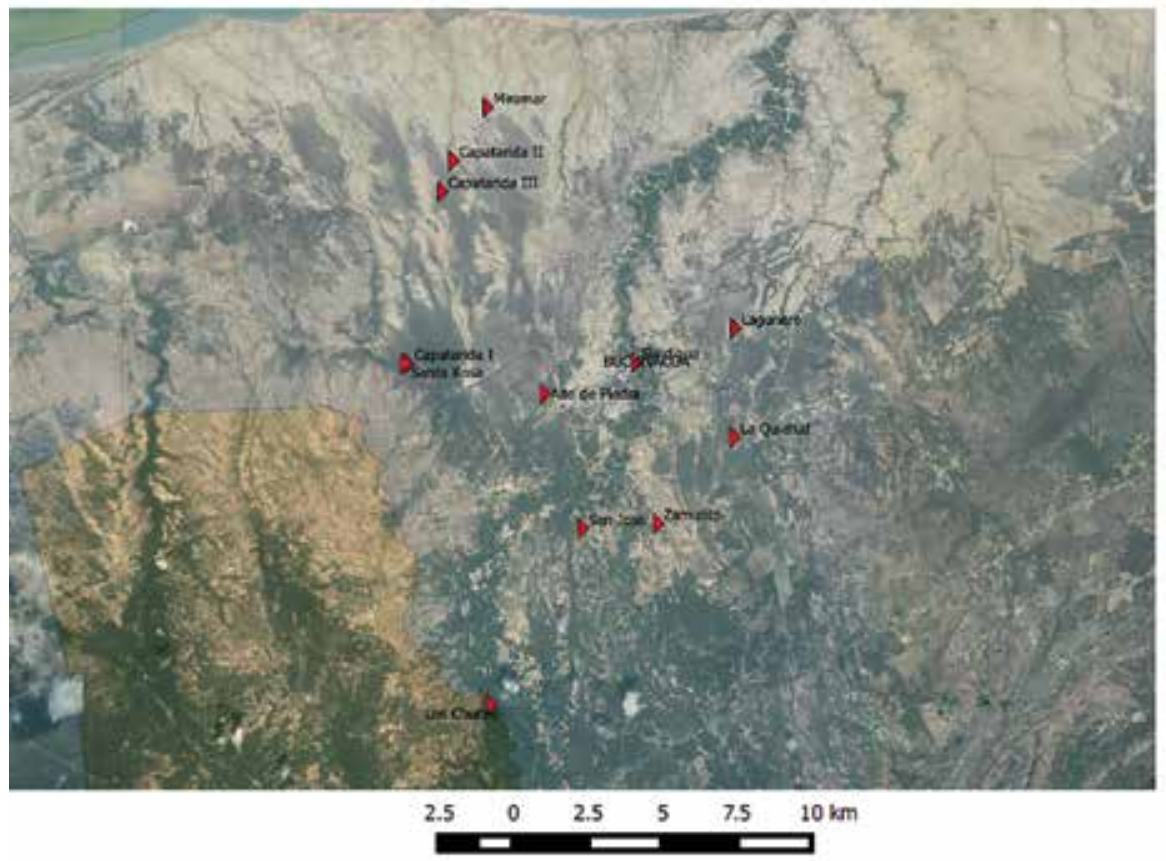

Figura 3. Ubicación de los pozos zona Capatárida.

Fuente: elaborado con datos tomados del SIG QGIS V2.12.1.

Debido a que esta investigación está enmarcada dentro de un proyecto de investigación que contribuye al mejoramiento de las condiciones de vida de la comunidad, se abarcaron solo aquellos pozos cuyo impacto está relacionado directamente con el municipio, es decir, aquellos cuyo 
resguardo y manejo son responsabilidad de la comunidad o los consejos comunales. Se tomaron como referencia los datos obtenidos en la caracterización del pozo Borojó, ya que estos resultados son relativamente similares respecto al resto de los pozos analizados.

Tabla 4. Parámetros físicos

\begin{tabular}{lrrrl}
\hline \multicolumn{1}{c}{ Parámetros } & & & \multicolumn{1}{c}{$\begin{array}{c}\text { Valores máximos } \\
\text { aceptables }\end{array}$} \\
\hline Conductividad, $\mu \mathrm{S} / \mathrm{cm}$ & 847.00 & 0 & 0 & S.V.G (sin valor guía) \\
Temperatura, ${ }^{\circ} \mathrm{C}$ & 35.9 & 0 & 0 & S.V.G (sin valor guía) \\
Turbiedad, NTU & 4.00 & 0 & 0 & $10 \mathrm{NTU}$ \\
Sólidos disueltos, $\mathrm{mg} / \mathrm{L}$ & 427.67 & 1.88 & 0.27 & 1000 \\
Sólidos totales, $\mathrm{mg} / \mathrm{L}$ & 956.67 & 9.03 & 5.36 & S.V.G (sin valor guía) \\
\hline
\end{tabular}

Tabla 5. Parámetros químicos

\begin{tabular}{lrrrl}
\hline \multicolumn{1}{c}{ Parámetros } & & & \multicolumn{1}{c}{$\begin{array}{c}\text { Valores máximos } \\
\text { aceptables }\end{array}$} \\
\hline $\mathrm{pH}$ & 7.90 & 0 & 0 & 9 \\
Salinidad, ppt & 0.4 & 0.01 & 1.66 & S.V.G (sin valor guía) \\
Alcalinidad, mg/L & 150.67 & 9.42 & 2.57 & S.V.G (sin valor guía) \\
Acidez, mg/L & 28.00 & 0 & 0 & S.V.G (sin valor guía) \\
Dureza total, mg/L & 298.67 & 6.28 & 0.93 & 500 \\
Oxígeno disuelto, ppm & 4.58 & 0.01 & 0.07 & S.V.G (sin valor guía) \\
Cloruros, mg/L & 59.32 & 5.44 & 1.89 & 300 \\
Nitrógeno, mg/L & 49.99 & 0 & 0 & S.V.G (sin valor guía) \\
Fósforo, mg/L & $<\mathrm{CMD}$ & 0 & 0 & S.V.G (sin valor guía) \\
Sulfatos, mg/L & 1.58 & 0.03 & 2.38 & 500 \\
Índice de Langelier & 1.02 & 0 & 0 & S.V.G (sin valor guía) \\
\hline
\end{tabular}

Los valores expuestos en las tablas pueden ser considerados como valores representativos. La desviación estándar indica poca dispersión de los datos respecto a la media y que los coeficientes de variación alrededor del valor medio son pequeños.

Respecto a la salinidad, los valores del conductímetro se expresan en ppt (parts per thousand 'partes por mil'), aunque también pueden ser expresadas en $\mathrm{g} / \mathrm{L}$.

El contenido de sal en agua potable se establece menor a $0.05 \%$. Por encima de este valor, el agua es señalada como salobre, o definida como salina si contiene de 3 a $5 \%$ de sal en volumen. Por encima de $5 \%$ se la considera salmuera. (Universidad Autónoma de Chiapas, 2010)

El agua de los pozos analizados se categorizó como salobre.

Respecto al índice de Langelier, la mayoría de los pozos presentan valores positivos. Flores (2011) afirma que:

Un valor positivo del índice de saturación indica que el agua está sobresaturada y puede precipitar carbonato de calcio, un valor negativo indica que el agua es corrosiva y disolverá las incrustaciones de carbonato de calcio; este índice de saturación sirve como una indicación de la tendencia del agua a disolver o precipitar carbonato de calcio, pero no indica la cantidad de precipitado. Es importante 
para poder controlar la incrustación o la corrosión en las redes de distribución del agua y para las instalaciones interiores domésticas. (pp. 27-28)

Tabla 6. Metales

\begin{tabular}{lrrll}
\hline \multicolumn{1}{c}{ Parámetros } & $\overline{\boldsymbol{x}}$ & $\boldsymbol{S}$ & $\% \mathrm{CV}$ & $\begin{array}{c}\text { Valores máximos } \\
\text { aceptables }\end{array}$ \\
\hline Potasio, $\mathrm{mg} / \mathrm{L}$ & 3.96 & 0 & 0 & S.V.G (sin valor guía) \\
Sodio, $\mathrm{mg} / \mathrm{L}$ & 99.00 & 0 & 0 & S.V.G (sin valor guía) \\
Hierro, $\mathrm{mg} / \mathrm{L}$ & 0.80 & 0 & 0 & 0.3 \\
Cobre, $\mathrm{mg} / \mathrm{L}$ & $<0.01$ & 0 & 0 & 1 \\
Manganeso, $\mathrm{mg} / \mathrm{L}$ & $<0.01$ & 0 & 0 & 0.5 \\
Zinc, $\mathrm{mg} / \mathrm{L}$ & $<0.01$ & 0 & 0 & 5 \\
Níquel, $\mathrm{mg} / \mathrm{L}$ & $<0.01$ & 0 & 0 & S.V.G (sin valor guía) \\
\hline
\end{tabular}

Tabla 7. Parámetros microbiológicos

\begin{tabular}{lllll}
\hline \multicolumn{1}{c}{ Parámetros } & $\bar{x}$ & $s$ & $\% C V$ & \multicolumn{1}{c}{$\begin{array}{c}\text { Valores máximos } \\
\text { aceptables }\end{array}$} \\
\hline $\begin{array}{l}\text { Coliformes totales, } \\
\text { (NMP/100mL) }\end{array}$ & 0 & 0 & 0 & $<2$ \\
$\begin{array}{l}\text { Escherichia coli, (NMP/mL) } \\
\text { Salmonella en 25mL }\end{array}$ & 0 & 0 & 0 & $\begin{array}{l}\text { Mín. } 9.0 \\
\text { Máx. } 93.0\end{array}$ \\
$\begin{array}{l}\text { Esporas de bacterias } \\
\text { formadoras de viscosidad, }\end{array}$ & 0 & 0 & 0 & 0 \\
(esp/g) & 0 & 0 & 0 & Mín. $1.0 \times 10^{2}$ \\
\hline
\end{tabular}

Tabla 8. Pozos que exceden los valores guía o valores permisibles

\begin{tabular}{|c|c|c|c|}
\hline Parámetros & Resultado promedio & & Pozos \\
\hline Dureza total (mg/L) & $>500$ & $\begin{array}{l}\text { Capatárida I } \\
\text { Santa Rosa } \\
\text { Curuquebo } \\
\text { Zazárida } \\
\text { Canepe }\end{array}$ & $\begin{array}{l}\text { San José } \\
\text { Los Chucos } \\
\text { Zamurito } \\
\text { Santa Clara }\end{array}$ \\
\hline Hierro (mg/L) & 0.1 & $\begin{array}{l}\text { Capatárida I } \\
\text { Capatárida II } \\
\text { Capatárida III } \\
\text { Zamurito } \\
\text { Santa Clara } \\
\text { Canepe } \\
\text { Vijaguita II } \\
\text { El Copey } \\
\text { Vidare Adentro } \\
\text { El Calado } \\
\end{array}$ & $\begin{array}{l}\text { Altos de Piedra } \\
\text { Santa Rosa } \\
\text { San José } \\
\text { Los Chucos } \\
\text { Sividigua } \\
\text { Taparito } \\
\text { Derramadero } \\
\text { Las Peñitas } \\
\text { Vidare Afuera }\end{array}$ \\
\hline Manganeso (mg/L) & $0.1-0.5$ & $\begin{array}{l}\text { Altos De Piedra } \\
\text { Zamurito } \\
\text { Vijaguita II }\end{array}$ & $\begin{array}{l}\text { Las Peñitas } \\
\text { Vidare Adentro } \\
\text { Vidare Afuera }\end{array}$ \\
\hline
\end{tabular}




\begin{tabular}{llll}
\hline \multicolumn{1}{c}{ Parámetros } & Resultado promedio & \multicolumn{2}{c}{ Pozos } \\
\hline Salinidad (ppt) & $>0.05$ & $\begin{array}{l}\text { Todos los pozos presentan salinidades por encima de los } \\
0.05 \mathrm{ppt}\end{array}$ \\
\hline & & Capatárida III & San José \\
Coliformes totales & $>2$ & Miramar & Los Chucos \\
$(\mathrm{NMP} / 100 \mathrm{ml})$ & & Altos de Piedra & Zamurito \\
& & Santa Rosa & \\
\hline
\end{tabular}

En vista de que para la mayoría de los pozos los resultados bacteriológicos arrojaron resultados negativos para coliformes totales, no fue necesario realizar muestreos y análisis adicionales, salvo en los siete pozos donde el número más probable (NMP) fue superior a lo establecido en las normas para agua potable (ver tabla 8).

Los pozos con presencia de bacterias coliformes totales merecen un análisis profundo, ya que en las sucesivas repeticiones se obtuvo un NMP superior a los valores máximos reportados en las normas venezolanas. Uno de estos fue el pozo Miramar, el más explotado, cuya profundidad es de $30 \mathrm{~m}$ y está cercano a viviendas y a un relleno sanitario. Esta contaminación se denomina localizada, la cual, según Hernández (2014), puede originarse "por el lavado de todas aquellas fuentes de contaminantes mal impermeabilizadas como pueden ser: vertederos de residuos urbanos o industriales, fosas sépticas, donde el cono de depresión originado ayuda a la propagación de la contaminación" (p. 97).

Es importante realizar una correlación de los pozos contaminados (los cuales están cercanos a los centros poblados) y determinar la profundidad de cada uno para tomar medidas que permitan disminuir o evitar su contaminación.

Para los casos con resultados de NMP de coliformes, el Decreto 2048 de 1997, Normas para la Ubicación, Construcción, Protección, Operación y Mantenimiento de Pozos Perforados Destinados al Abastecimiento de Agua Potable, establece que:

La desinfección de un pozo deberá practicarse utilizando cloro u otros desinfectantes de efecto residual. La solución de cloro utilizada para la desinfección de un pozo perforado deberá tener una concentración no menor de $50 \mathrm{mg} / \mathrm{L}$. La concentración indicada deberá mantenerse después de un período de contacto no menor de 30 minutos. (art. 57)

La clasificación del agua de los pozos estudiados se estableció de acuerdo a los criterios del Decreto 883 de 1995, Normas para la Clasificación y el Control de la Calidad de los Cuerpos de agua y vertidos o Efluentes Líquidos:

Sub Tipo 1B: Aguas que pueden ser acondicionadas por medio de tratamientos convencionales de coagulación, floculación, sedimentación, filtración y cloración.

Sub Tipo 1C: Aguas que pueden ser acondicionadas por proceso de potabilización no convencional [ablandamiento, aireación, ósmosis inversa]. (art. 3)

A partir de la comparación con las normas para agua potable, se pueden agrupar los distintos pozos por parámetro excedido, con la finalidad de facilitar el diseño de esquemas de tratamiento adecuados por zona estudiada. Esta información se puede apreciar en la tabla 8.

Según los parámetros fisicoquímicos usados en este estudio, los pozos estudiados tienen por lo general características relativamente similares.

Según los límites permisibles para agua potable establecidos por la Gaceta n. ${ }^{\circ}$ 36395, estas aguas deben ser tratadas a través de un proceso de desalinización para garantizar la calidad fisi- 
coquímica del agua debido a que son aguas salobres, aunque los pozos no tienen problemas de contaminantes en el agua.

A partir de los resultados obtenidos y de la clasificación de los pozos estudiados, es posible obtener un esquema único que permita el tratamiento de las aguas por procesos de potabilización convencionales y no convencionales.

El agua subterránea que proviene de los pozos llega al sistema de potabilización a través de tuberías y por sistema de bombeo. Dichos efluentes ingresan a un tanque de ablandamiento con hidróxido de calcio $\left(\mathrm{Ca}(\mathrm{OH})_{2}\right)$ para eliminar la dureza causada por las presencia de iones calcio $\left(\mathrm{Ca}^{2+}\right)$ y magnesio $\left(\mathrm{Mg}^{2+}\right)$ disueltos en el agua. Posteriormente, el efluente pasa a un proceso de filtración con aireación para eliminar por oxidación las concentraciones de hierro $(\mathrm{Fe})$ y manganeso $(\mathrm{Mn})$ y luego es sometido a un proceso de ósmosis inversa para eliminar el exceso de cloruros y salinidad provenientes del agua subterránea. Finalmente, se aplica un proceso de desinfección química con hipoclorito de sodio $(\mathrm{NaOCl})$ para alcanzar la calidad del agua establecida para el consumo humano. El esquema planteado se aprecia en la figura 4.

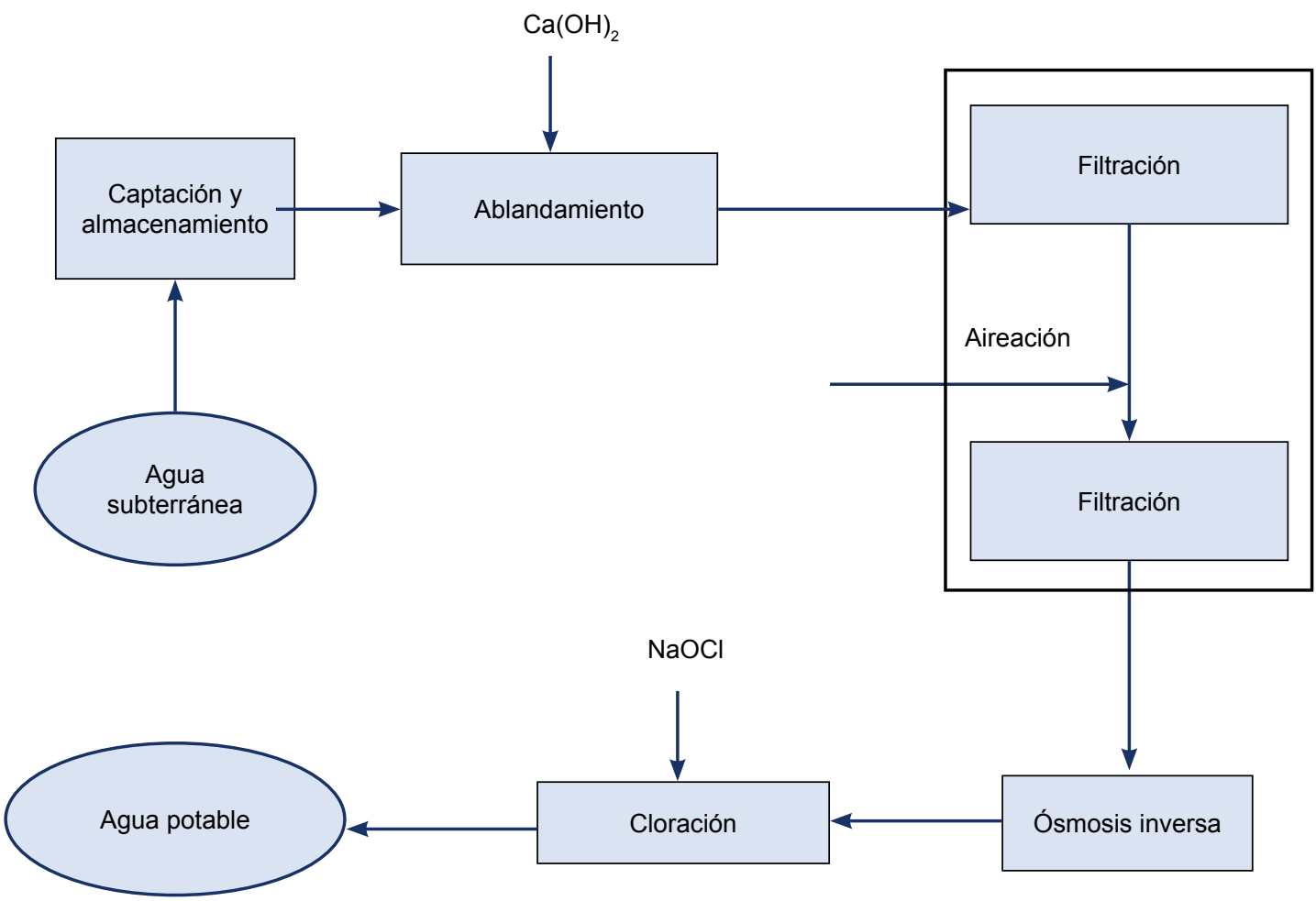

Figura 4. Esquema de tratamiento propuesto para aguas subterráneas en el municipio Buchivacoa, estado Falcón, Venezuela.

Este esquema propuesto sirve como punto de partida para ingenierizar los procesos de potabilización, lo que deberá tener el apoyo de las instituciones regionales responsables del agua y la salud de la comunidad y cumplir con los requerimientos técnicos y económicos disponibles. Los procesos presentados en el esquema se derivan de las características de los pozos agrupados por zonas, lo que representa un esquema único que permite adecuar las características de esas aguas subterráneas para el consumo de los habitantes de las localidades del municipio Buchivacoa. 
El papel de una comunidad organizada para la solución a la problemática de la localidad respecto al acceso al agua potable es determinante, así como la capacitación en la administración y mantenimiento de los mismos, pues esto permite que se haga sustentable.

\section{Conclusiones}

La mayoría de los pozos analizados cumplen con el criterio microbiológico para aguas de consumo humano. Ninguna muestra indica la presencia de microorganismos causantes de enfermedades ni de bacterias coliformes.

Las aguas provenientes de los pozos profundos del municipio Buchivacoa pueden ser aptas para consumo humano siempre y cuando se acondicionen por medio de tratamientos convencionales y no convencionales.

El esquema sugerido para el tratamiento de hierro, dureza y coliformes totales y termorresistentes es filtración, ablandamiento con resinas catiónicas, ósmosis inversa y desinfección química con cloro en solución.

\section{Agradecimientos}

Al proyecto PEII 20130001815, del Programa de Estímulo a la Investigación e Innovación del FONACIT del Ministerio del Poder Popular para Ciencia Tecnología e Innovación MPPCTI, por el financiamiento de la investigación. A la Universidad Nacional Experimental "Francisco de Miranda”. A la Alcaldía Bolivariana del municipio Buchivacoa, estado Falcón. A la unidad territorial de Fundacite Falcón. A los consejos comunales del municipio Buchivacoa.

\section{REFERENCIAS}

Centro Panamericano de Ingeniería Sanitaria y Ciencias del Ambiente. (2004). Operación y mantenimiento de plantas de tratamiento de agua: manual de capacitación para operadores (tomo I-VI). Lima: CEPIS-OPS

Collazo, M., y Montaño, J. (2012). Manual de Agua Subterránea. Montevideo: Ministerio de Ganadería, Agricultura y Pesca.

Decreto 883 de 1995. Normas para la clasificación y control de la calidad de los cuerpos de agua y vertidos o efluentes líquidos. Gaceta Oficial de la República de Venezuela 11 de octubre de 1995.

Flores, S. (2011). Evaluación del tratamiento de las aguas de producción desde una planta de inyección de agua salada hasta pozos inyectores del campo Mata-R PDVSA Gas Anaco (tesis de Ingeniería Química). Departamento de Ingeniería Química, Universidad de Oriente, Cumaná, Venezuela.

Gaceta Oficial de la República de VenezuelaSG-018-98 Normas Sanitarias de calidad de agua potable. Número SG-018-98 11de febrero de 1998.

Hernández, M. (2014). Estudio de viabilidad ecológica de la tecnología de fracturación bidráulica (trabajo de grado). Departamento de Explotación de Recursos Minerales y Obras Subterráneas, Escuela Técnica Superior de Minas y Energía, Universidad Politécnica de Madrid, Madrid, España.

Reyes, E. (2016). Evaluación de fuentes de agua subterránea para las comunidades de Zazárida, Bariro y Goajiro del municipio Buchivacoa del estado Falcón (trabajo de grado). Universidad Nacional Experimental Francisco de Miranda, estado Falcón, Venezuela. 
NOEL ACACIO CHIRINO, JONNATTAN CANCINO CAMPEROS, MANUEL MOLINA CÉSPEDES

Universidad Autónoma de Chiapas. (2010). Salinidad. Recuperado de http://ingagronomiacmu. blogspot.com/2010/02/salinidad_23.html.

Universidad Simón Bolívar. (2006). Evaluación de la posible intrusión marina y salinización de pozos costeros en áreas piloto al norte de Tocópero y Puerto Cumarebo, Estado Falcón (informe n. ${ }^{\circ}$ ). Venezuela: Grupo de Física Nuclear-USB. 